\title{
Comparative Study on Compressive Strength of Demolished Concrete Aggregate and Conventional Concrete Aggregate for Construction Materials
}

\author{
Basha Fayissa $^{1}$ \\ Jimma University Instiute of Technology \\ Facul of Civil and Environmental \\ Engineering, Jimma, Ethiopia
}

\author{
Anteneh Geremew \\ Jimma University Instiute of Technology \\ Facul of Civil and Environmental \\ Engineering, Jimma, Ethiopia
}

\begin{abstract}
Recycling and waste reduction both are extremely important elements in the framework of waste management, because they help to preserve mainly the natural resources and reduce demand for valuable landfill space. Demolition and construction waste quantities posing an adverse effect on the environment. Utilization of such waste as recycled aggregate in concrete can be useful both for environmental protection and economical aspects in the construction industry. In this research, the use of recycled concrete aggregate in the concrete and the effects on its compressive strength by progressively replacing the natural concrete aggregate (NCA) with recycled aggregate was studied. It was the experimental study of recycled concrete aggregate (RCA) when it was compared with the natural concrete aggregate on account of its physical properties. Cubes having dimension $150 \times 150 \times 150 \mathrm{~mm}^{3}$ were casted using recycled aggregate by replacing the natural aggregate by $0 \%, 25 \%$, $50 \%$ and $75 \%$ and corresponding results of compressive strengths were recorded. The compressive strengths were recorded by crushing the cube at $7,14,21$ and 28 days and it was found that performance of concretes with $0 \%$ and $25 \%$ replacement of natural aggregate by recycled aggregate were quite similar to concrete without replacement but with $50 \%$ and $75 \%$ replacement, the strength of concrete was decreased.
\end{abstract}

Keywords: Recycled Aggregate, Concrete, Compressive Strength, Natural Concrete and Slump Value

\section{INTRODUCTION}

Recycling and waste reduction both are extremely important elements in the framework of waste management, because they help to preserve mainly the natural resources and reduce demand for valuable landfill space (Ling et al., 2013). Utilization of such waste as recycled aggregate in concrete can be useful both for environmental protection and economical aspects in the construction industry (Salim Khoso, 2015). Any construction activity requires several materials such as concrete, steel, brick, stone, glass, clay, mud, wood, and so on. However, the cement concrete remains the main construction material used in construction industries. For its suitability and adaptability with respect to the changing environment, the concrete must be such that it can conserve resources, protect the environment, economize and lead to proper utilization of energy. To achieve this, major emphasis must be laid on the use of wastes and by-products in cement and concrete used for new constructions (Salim K. et al., 2015).

The utilization of recycled aggregate is particularly very promising as 75 percent of concrete is made of aggregates. In that case, the aggregates considered are slag, power plant wastes, recycled concrete, mining and quarrying wastes, waste glass, incinerator residue, red mud, burnt clay, sawdust, combustor ash and foundry sand. The enormous quantities of demolished concrete are available at various construction sites, which are now posing a serious problem of disposal in urban areas. This can easily be recycled as aggregate and used in concrete (Salim K. et al., 2015).

Management of solid waste is a serious challenge faced globally. However, it is a particular problem in the gulf region, where most countries have the highest per capita waste generation in the world. Industrial growth, construction booms, rapid urbanization, changing lifestyles, and unsustainable consumption patterns, have all contributed to this growing waste problem. Accelerated urbanization has led to the spending of billions on construction for infrastructure and public sector building programs, which has resulted in an increasing need for construction materials and the management of related construction wastes. After demolition of old roads and buildings, tons of construction waste are discarded; the removed concrete is also often considered worthless and disposed of as demolition waste. The majority of construction waste is considered as an inert and can potentially be used for recycled construction materials (Shahid K. et al., 2016).

Concrete waste from demolished activities is seldom used as recycled concrete aggregate. To achieve sustainability in construction, researches and companies focus on using waste concrete as a new construction material. Many researchers have been done and the utilization of recycled concrete has been done in construction of pavements and drainages, embankments, bases and sub-bases. However the number of successful incorporations in replacement of recycled aggregate with normal aggregate is very limited 
due to lack of suitable laws, guidelines, experience in utilization and low quality. Moreover limited usage or no usage of this demolished concrete is an environmental hazard since it requires a large re for disposal. Hence one has to look forward for effective utilization of demolished concrete in order to rescue the depleting natural aggregates and reduce the environmental degradation (Shathem J., 2016).

The construction and demolition industry fact file stated that the usage of stones from previous roads in rebuilding new set of roads is dated since Romans Empire. The main problem while incorporating the usage of demolished concrete is with the sources $\mathrm{f}$ demolished aggregates as demolished wastes may not be from the same source and workability. The problem with workability can be reduced by using super plasticizers and many researchers conducted reveals that source have a little effect on strength of recycled aggregate concrete (RAC) and the variation of strength RAC is not very significant and Recycled aggregates can be used for regular constructions as the strength falls in the nominal range. (Shathem J., 2016).

\section{SCOPE OF THE STUDY}

Many research studies have been conducted on the utilization of RCA for construction materials of different structures. The aim of this study was the laboratory examination of the physical and mechanical properties of the RCA and its utilization in construction for the realization of its applicability in building construction by trial and error through mechanical stabilization. This has been compared with Standard Specifications, it was indicated that good response has been observed.

\section{SIGNIFICANCE OF THE STUDY}

The significance of this study would incur the merit of realization of utilization of RCA materials by mechanical stabilization, conservation of construction material, reduction of the wastage of demolished and construction material, development of construction material option for the local contractors, improvement of the quality of materials and reduction of environmental pollution faced by demolished concrete.

\section{MATERIALS}

The following materials were used in the entire investigations of this study.

\subsection{Cement}

According to IS 15658/2006, Ordinary Portland Cement of Grade 53 is used, which is conformed to IS 12269. A 53 grade cement is a prime brand cement with a remarkably high $\mathrm{Ca}_{3}$ (tricalcium providing long-lasting) durability of concrete constructions. It produces highly durable and sound concrete due to really low percentage of alkalis chlorides, magnesia cement which is used in the experimental work of Ordinary Portland Cement of grade 53 conformed to IS 12269 . The physical properties of the cement are examined by conducting appropriate tests as per IS $269 / 4831$.

\subsection{Water}

A water which is used in the concrete production is conformed to the specification of IS 456/2000. A water is used for mixing is free from injurious amount of oils, acids, alkalis, salts, sugar, organic materials or other substances that may be deleterious to concrete.

\subsection{Recycle Aggregate}

Recycle aggregate is a waste material collected from demolished concrete structure. For this study, the recycle aggregate is collected from a demolished concrete structure (Jimma Ginjo Guduru Bethel Mechane Yesus Church building) situated near Kochi bajaj station. This material is used after strictly passing from $20 \mathrm{~mm}$ IS sieve.

\subsection{Fine Aggregate}

The natural river sand conforming to Zone II as per IS $383 / 1987$ is used. The fineness modulus of sand used is 2.20 with a specific gravity of 2.6.

\subsection{Coarse Aggregate}

The crushed granite coarse aggregate conforming to IS $383 / 1987$ is employed.

\section{METHODOLOGY}

The experimental work was conducted in the Jimma Institute of Technology laboratory of Civil engineering department. The coarse aggregate (C.A) was separated from the concrete by hammering. Mortar adhered to the aggregate is also removed from the aggregate as much as possible. Obtained C.A is sieved under $20 \mathrm{~mm}$ sieve (passing) and $4.75 \mathrm{~mm}$ sieve (retained), later these aggregates can be used as R.C.A for further work. Natural aggregate was replaced by recycled aggregate with various percentages of $0 \%, 25 \%, 50 \%, 75 \%$ and $100 \%$ correspondingly. The compressive strengths were noted by crushing the cubes at 7,14,21 and 28 days of curing.

\section{RESULTS AND DISCUSSIONS}

Mechanical properties of recycled aggregate and natural aggregate

Table 1. Properties of N.A, R.A. aggregates and Sand

\begin{tabular}{|l|c|c|c|}
\hline Properties of aggregate & N.A & R.A & Sand \\
\hline Sp. Gravity & 2.61 & 2.57 & 2.56 \\
\hline Elongation index (\%) & 24.82 & 16.81 & -- \\
\hline Flakiness index (\%) & 19.43 & 10.21 & -- \\
\hline $\begin{array}{l}\text { Bulk unit weight } \\
\left(\mathrm{kg} / \mathrm{m}^{3}\right)\end{array}$ & 1611.4 & 1423.2 & 1613 \\
\hline Water absorption (\%) & 1.13 & 6.69 & 1.01 \\
\hline Impact value (\%) & 17.34 & 28.26 & -- \\
\hline Crushing value (\%) & 18.59 & 26.73 & -- \\
\hline Moisture content (\%) & 1.01 & 3.01 & 2.04 \\
\hline
\end{tabular}

Based on the above experiment results, the specific gravity, the elongation index, the flakiness index, the bulk unit weight, the absorption capacity, the impact value and the crushing value of the recycled coarse aggregate is less than the natural aggregate. 
Table 2. Slump test results of specimens

\begin{tabular}{|c|c|c|}
\hline Grade of concrete & Mix ratio & Slump (mm) \\
\hline C- 25 & $0 \%$ R.A + 100\% N.A & 30 \\
\hline C- 25 & $25 \%$ R.A $+75 \%$ N.A & 15 \\
\hline C-25 & $75 \%$ R.A + 25\% N.A & 10 \\
\hline C-25 & $100 \%$ R.A + 0\% N.A & 0 \\
\hline
\end{tabular}

The slump test result indicated that using the Recycle coarse aggregate up to $24 \%$ in concrete does not affect the compressive strength of the concrete. Addition of the more than $24 \%$ of recycled concrete aggregate reduces the compressive strength of the concrete.

Table 3. Compressive strength results of cube tests

\begin{tabular}{|c|c|c|c|c|}
\hline \multirow{2}{*}{ Mix ratio } & \multicolumn{3}{|c|}{ Compressive Strength $\left(\mathrm{N} / \mathrm{mm}^{2}\right)$} \\
\cline { 2 - 4 } & 7 Days & 14 Days & 21 Days & 32.08 \\
\hline 0\% R.A + 100\% N.A & 23.53 & 28.32 & 28 Days & 36.91 \\
\hline 25\% R.A + 75\% N.A & 22.81 & 27.34 & 29.33 & 29.11 \\
\hline 50\% R.A + 50\% N.A & 22.66 & 23.46 & 28.18 & 29.90 \\
\hline 75\% R.A + 25\% N.A & 22.37 & 22.56 & 14.56 & 29.51 \\
\hline 100\% R.A + 0\% N.A & 12.24 & 13.43 & 15.87 \\
\hline
\end{tabular}

Table 4. Gradation analysis of N.A and R.C.A

\begin{tabular}{|c|c|c|}
\hline \multirow{2}{*}{ Sieve size $(\mathrm{mm})$} & Natural Aggregate & Recycled Aggregate \\
\cline { 2 - 3 } & Percentage passing (\%) & Percentage passing (\%) \\
\hline 37.5 & 100 & 86 \\
\hline 28 & 96 & 53 \\
\hline 20 & 52 & 17 \\
\hline 12.5 & 16 & 8 \\
\hline 10 & 3 & 1 \\
\hline 4.75 & 0 & 0 \\
\hline Pan & -- & \\
\hline
\end{tabular}

Table 5. Gradation analysis of sand

\begin{tabular}{|l|c|c|c|c|c|c|c|c|}
\hline Sieve size (mm) & 9.5 & 4.75 & 2.36 & 1.18 & 0.6 & 0.3 & 0.15 & Pan \\
\hline Percentage passing (\%) & 100 & 99 & 96 & 88 & 58 & 29 & 9 & 0 \\
\hline
\end{tabular}

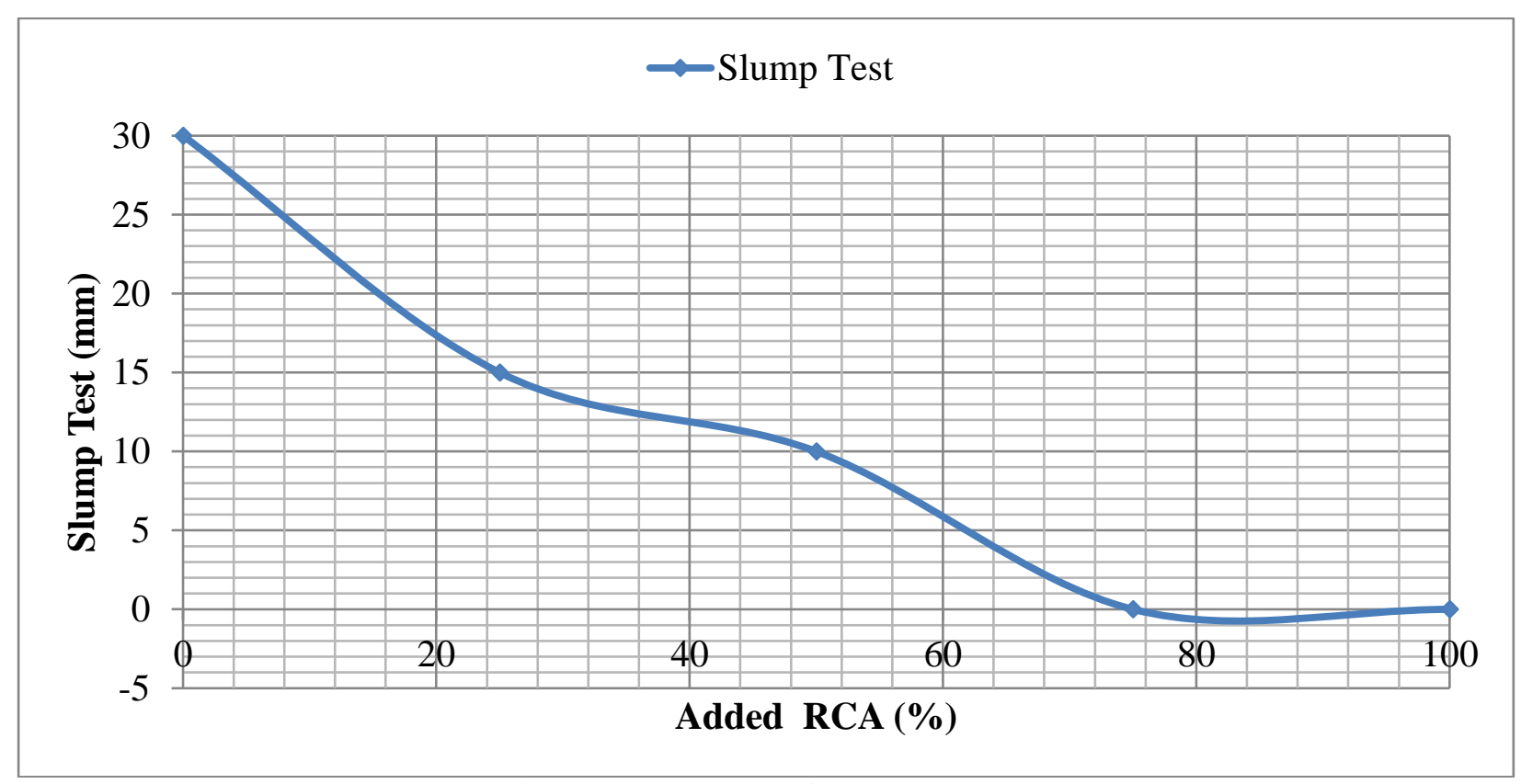

Figure 1: Slump Test result of C-25 concrete grade 


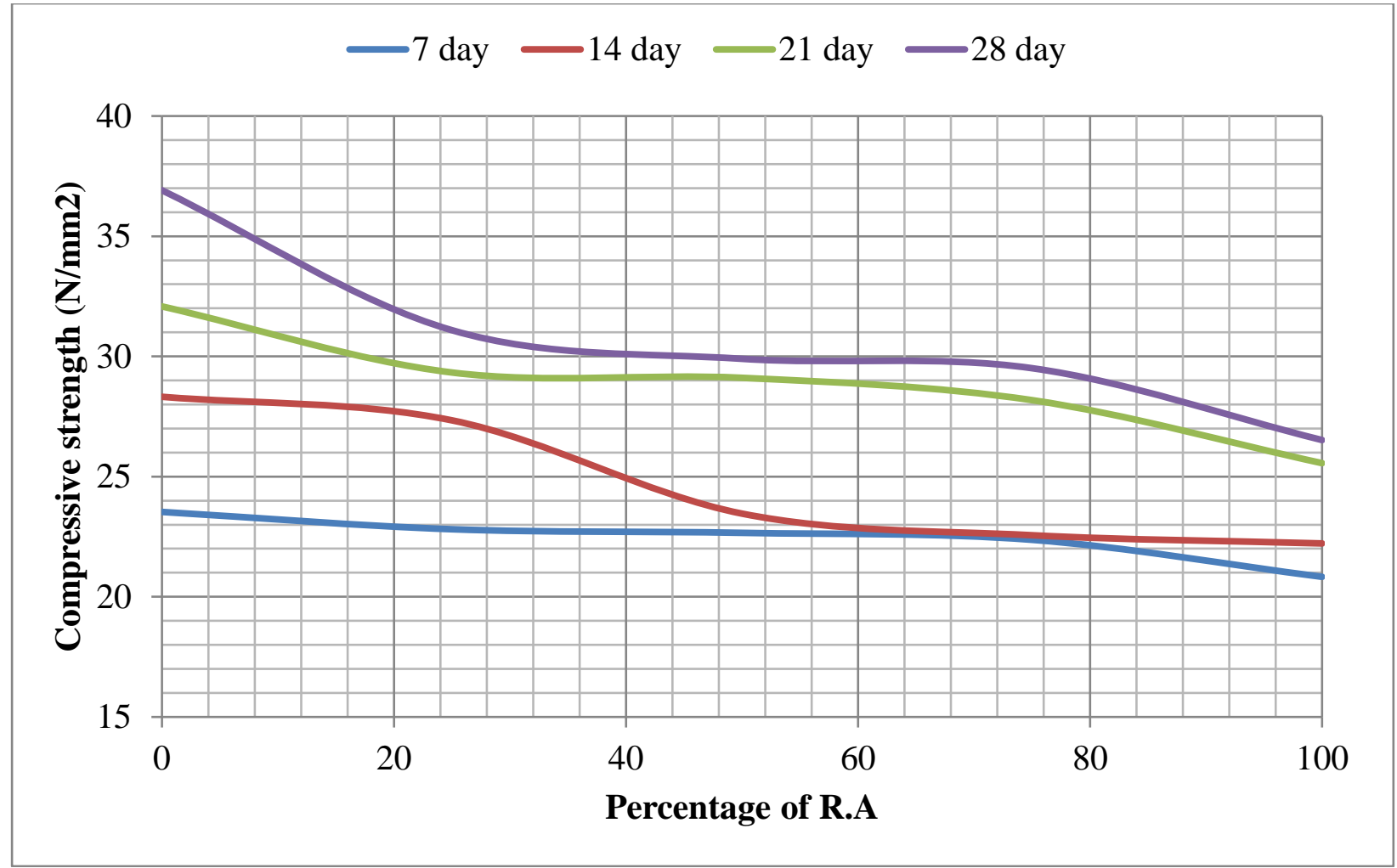

Figure 2: Compressive strength test result of C-25 concrete grade

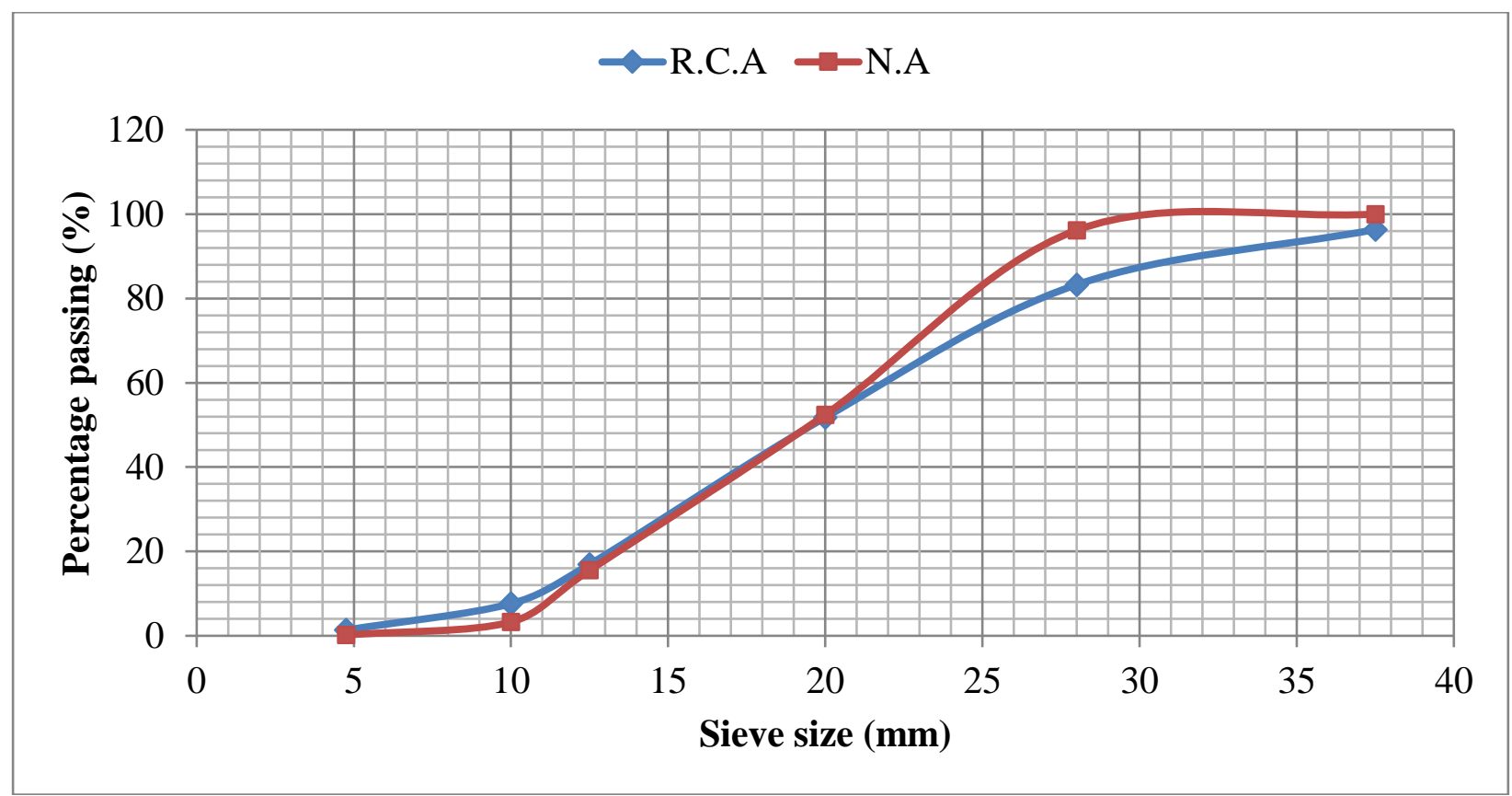

Figure 3: Gradation analysis of N.A and R.C.A 


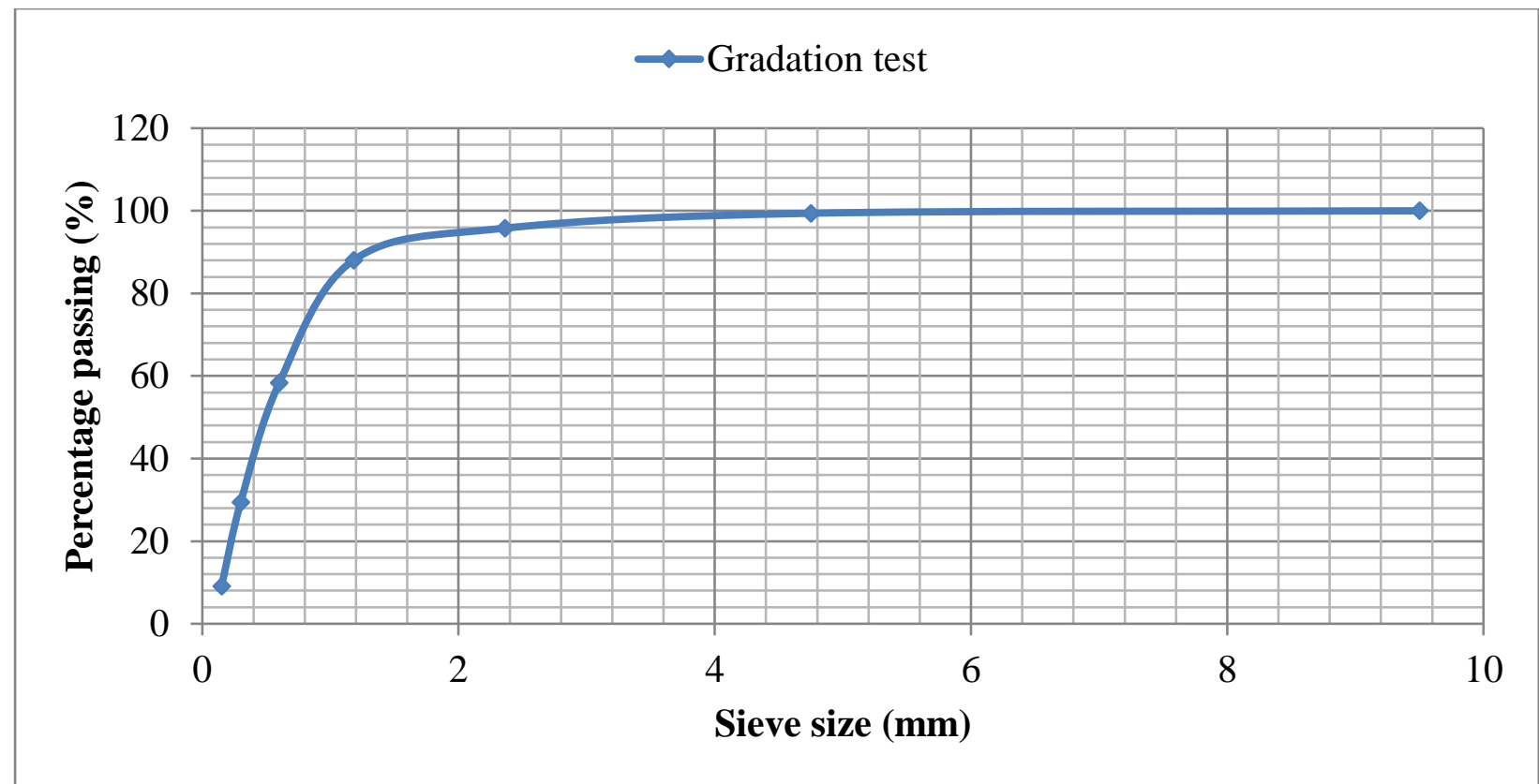

Figure 4: Gradation test for natural sand

\section{CONCLUSIONS}

The compressive strengths of demolished concrete aggregate (R.C.A) 12.24, 13.43, 14.56 and 15.87 Mpa for $7,14,21$ and 28 days respectively which was unacceptable for concrete structure construction works for that it revealed fewer results than the standard. The compressive strengths of natural aggregate (R.C.A) 23.53, 28.32, 28.02 and $36.91 \mathrm{Mpa}$ for 7, 14, 21 and 28 days respectively which was acceptable for concrete structure construction works for that it revealed greater results than the standard. As the percentage of recycled coarse aggregate was increased the compressive strength and the slump of the concrete decreased correspondingly. As observed from the slump test result, addition of more than $50 \%$ of recycled coarse aggregate increases the absorption capacity which reduces the compressive strength of the concrete. Blending recycle coarse aggregate with natural aggregate up to $75 \%$ in concrete does not affect the compressive strength of the concrete.

\section{RECOMMENDATIONS}

So it was advisable to use 25 to $50 \%$ recycled coarse aggregate in low rise structure, pavement design, drainage structure, road construction etc. This fill also resolve environmental issues raised due to dumping of demolition debris and construction waste. The recycled concrete aggregate should be studied by the using chemical stabilization to improve the strength of concrete beyond the $50 \%$ for slump test and beyond $75 \%$ for compressive strength

\section{REVERENCES}

[1] Haifang Wen, David I. McLean, Spencer Boyle, Timothy Spry, Danny Mjelde. (2014). Evaluation Of Recycled Concrete As Aggregate In New Concrete Pavements. Washington State Transportation Center (TRAC), P-63-66.

[2] Haifang Wen, David I. McLean, Spencer Boyle, Timothy Spry, Danny Mjelde. (2014). Evaluation Of Recycled Concrete As Aggregate In New Concrete Pavements. Washington State Transportation Center (TRAC), P-60-66.

[3] I. González-Taboada, B. González-Fonteboa , F. MartínezAbella, D. Carro-López. (2016). Study of recycled concrete aggregate quality and its relationship with recycled concrete compressive strength using database analysis. Materiales de Construccion, Vol. 66, Issue 323, ISSN-L: 0465-2746.

[4] Qin Li, Chunhong Zhang. (2017). A Statistical Study on the Compressive Strength of Recycled Aggregate Concrete. The Italian Association of Chemical Engineering, VOL. 59, P-425.

[5] Salim Khoso, Abdul Aziz Ansari, Jam Shahzaib Khan, Farhan Hussain Wagan. (2015). Experimental Study On Recycled Concrete Using Dismantled Road Aggregate And Baggase Ash. 7th International International Civil Engineering Congress (ICEC-2015), 3.

[6] Vázquez, P. E. (2016). Recycled Aggregates for Concrete: Problems and Possible Solutions. International Journal of Earth \& Environmental Sciences, Volume 1. 2016. 122, ISSN: 2456-351X

[7] Zengfeng Zhao, Sébastien Remond, Denis Damidot, Weiya $\mathrm{Xu}$. (2015). Influence of fine recycled concrete aggregates on the properties of mortars. Construction and Building Material, ELSEVIER Ltd , P: 179-186. 